\title{
A Prospective Study of Blood Usage Pattern and Demand Supply Assessment in a Tertiary Care Hospital in India
}

\section{Surya Prakash Singh ${ }^{*}$ and Heena Nazreen}

Department of Clinical Pharmacy, Mahatma Gandhi Memorial (MGM) Hospital, Sherpura, Warangal, Telangana-506007, India

*Corresponding author: Surya Prakash Singh, Pharm D, Department of Clinical Pharmacy, Mahatma Gandhi Memorial (MGM) Hospital, Sherpura, Warangal, Telangana-506007, India, Tel: 91+ 8977716180; Fax: 501-686-6001; E-mail: surya.prakashsingh@yahoo.com

Received date: May 23, 2015, Accepted date: Oct 29, 2015, Publication date: Nov 04, 2015

Copyright: @ 2015 Singh SP, et al. This is an open-access article distributed under the terms of the Creative Commons Attribution License, which permits unrestricted use, distribution, and reproduction in any medium, provided the original author and source are credited.

\begin{abstract}
Background: Most patients of Mahatma Gandhi Memorial (MGM) Hospital receive blood transfusion from MGM Blood Bank, but representative data are lacking to substantiate this claim, and the characteristics of individuals who receive the transfusion have not been well described.
\end{abstract}

Aim and Objective: The main objective of the study was to assess the utilization pattern of blood and blood components and to assess their demand and supply in blood bank of MGM hospital, Warangal.

Material and Methodology: The data collection form was exclusively designed for data collection and entry. The analysis was done using MS-Access 2010 and Microsoft excel 2010. The statistical analysis was performed using SPSS22.0 $\mathrm{P} \leq 0.05$ as level of significance.

Results and Discussion: Most of the donors were found to be males (95\%) of which O positive 1077(40\%) were high in number. 23 infected donations were found in 2684 donations and were excluded from out study population. Age group of 20-29 were the highest donors and also the receptors. 2661 donations were supplied as 3225 units to 2223 patients, 2 unit transfusions was done in $481(21.6 \%)$ patients $>2$ transfusions was found in 197(8.85) patients. Highest number of requisitions were from general medicine ward and most indication was anemia (Includes various causes that may result in anemia, major being nutritional anemia) among which Females were most suffering group with anemia. There was no significant difference found between the average mean of donations per day ( $32.91 \pm$ $11.65)$ and average issues per day $(28.92 \pm 60.19)$ at $p<0.5333$. When the replacements and unsupplied units were considered the blood bank was able to supply only $85 \%$ of the requests and was falling short of supplies.

Conclusion: Periodic review of blood usage pattern is very essential in MGM hospital. Implementing a transfusion committee is essential for checking the appropriateness of transfusion.

Keywords: Demand supply assessment; Transfusion; Pattern of usage; Blood; Blood product usage; Usage survey

\section{Introduction and Background}

Blood transfusion is the pervasive form of tissue transplant performed day to day in the process of life saving in situations like severe anemia, trauma, and surgery. There is no an absolute standardized level for a transfusion, but the concept of, transfusion is only indicated when $\mathrm{Hb}<7 \mathrm{~g} / \mathrm{dl}$ has been general accepted in most of the countries in the world [1].

The blood component implies separation of whole blood into various potential components like packed red cells, Platelet rich plasma, fresh frozen plasma, cryoprecipitate and leucocytes [2-5] To maximize the effectiveness, safety and utility, clinicians and intravenous therapists should be erudite about the potential threat of blood component therapy. We should keep in mind that there should be an apt indication for ordering blood components as there is unnecessary exposure of the recipient to various infectious and noninfectious complications and avoid misuse. The vitality of the clinical audits performed at the clinical centers is self-explanatory and so it has become a part in quality assurance programmes [2]. Various strategies have been developed to reduce the inappropriate use of blood components. These include guidelines and consensus conferences as well as monitoring of transfusion practice, education, and self-audit by clinicians [5-8]. One being the assessment of the usage of blood and its appropriateness.

Most patients of MGM Hospital receive blood transfusion from MGM Blood Bank, but representative data is lacking to substantiate this claim, and the characteristics of individuals who receive the transfusion have not been well described. There is a need for continuous assessment of blood products usage as therapy, especially in a hospital where there is no transfusion committee "as in MGM Hospital".

This study shows the patterns of blood product usage in MGM and the balance of donations and issues. Using this study the management of MGM will be able to assess their status of blood mobilization and definitely benefited. Furthermore the data collected can also be used to assess the appropriateness of transfusions in MGM by doctors.

This study also proved the information about most prevailed disease or condition which requires transfusion and that information can be used in improving the treatment and management as well. 


\section{Aim and Objective}

The objectives of the study are as follows

1. Assess blood donors data and to characterize the same.

2. Study the various patterns of blood usage from blood bank, MGM Hospital, Warangal.

3. Assessment of demand and supply.

\section{Materials and Method}

\section{Study site}

The study was conducted at the Blood Bank, MGM Hospital, Warangal. MGM Hospital is a Tertiary care twelve hundred bedded Hospital, which is assumed to be the biggest Hospital in the Northern Telangana region of Andhra Pradesh State. Around 1200 patients per day are being treated for various diseases/disorders in various disciplines.

MGM Blood bank receives blood from the donors that will be supplied to the requested patients of MGM Hospital itself or to other government or private hospitals round the city as different blood components.

\section{Study period}

The study was carried out for 6 months of which data collection was performed for 3 months i.e January to March 2013. Later 3 months was for cleaning, analyzing the data generated and to prepare reports.

\section{Study design}

The study was designed to collect the patient data prospectively from the records of the patients and donors.

\section{Methods}

After getting permission from the blood bank, MGM hospital, Warangal, India, the data of three months i.e. January to March 2013 was collected from the record room each day.

A data collection form was exclusively designed for the purpose. The patient records were analyzed for following factors: Age, Sex, current diagnosis, and department, type of blood product indicated, number of units indicated and issued, issued free of cost, issued upon payment.

Donor's data was also collected in which was included of Name, age, sex, weight, Hemoglobin percentage, Blood Pressure, type of donation and blood screening result viz., blood groups and infections.

\section{Source of data}

The patient's data was from the physician's blood request forms that contain all necessary information about patient from the blood bank. Donor's data was accessed from ongoing registry books in blood bank.

\section{Inclusion criteria}

All the patients who were issued by blood units were included in the study irrespective of indications, sex, and age group.

\section{Exclusion criteria}

Blood units screened positive for the Infections Viz. HIV, HCV, HbsAg etc. were excluded from the study.

\section{Analysis of the data}

All the data was entered using MS-Access 2010 database and Charts were drawn using Microsoft excel 2010.

\section{Statistical analysis}

Graph Pad prism version 5.0 was used to analyze the data, using P $\leq$ 0.05 as level of significance.

\section{Results and Discussion}

Out of total 2684 units collected, HIV (Human Immune Deficiency Virus) and HCV (Hepatitis $C$ virus) infected units were one each and 21 units were of HBS-Ag (Hepatitis B Surface Antigen). The gender comparison of the donors is shown in "Figure 1 gender comparison of donors" in which male have made the most donations.

The method used for screening HIV was, anti-HIV1+ anti-HIV2 rapid assay. The tests used for $\mathrm{HCV}$ serological markers was $\mathrm{HCV}$ antibody/antigen and for HBS hepatitis B surface antigen test.

Out of 2684 donations received 2267 were voluntary donors and 417 were replacement donors who were.

Gender and age comparison of the blood units issued to the patients was analyzed and most receiving age group was found to be 20-29 [867(28.6\%)]. (Note: Age of infants and neonates were also considered as 1 year) as shown in "Figure 2 Age wise sex distribution". Of 3225 transfusion episodes in 2223 patients, 963(43.4\%) males and $1260(56.6 \%)$ were female. The distribution of transfusion units according to blood group include 629 units of A group, 155units of $\mathrm{AB}$ group, 995 units of $\mathrm{B}$ group and 1446 units of $\mathrm{O}$ group.

Among 1463 units requested for males, 278 units of A positive, 22 units of A negative, 438 units of $B$ positive, 16 units of $B$ negative, 69 units of $\mathrm{AB}$ positive, 1 unit of $\mathrm{AB}$ negative, 614 units of $\mathrm{O}$ positive and 25 units of $O$ negative were transfused.

Among 1762 units requested for females, 315 units of A positive, 14 units of A negative, 509 units of $B$ positive, 32 units of $B$ negative, 81 units of $\mathrm{AB}$ positive, 4 units of $\mathrm{AB}$ negative, 745 units of $\mathrm{O}$ positive and 62 units of $O$ negative were transfused.

Some patients had multiple episodes of transfusions which is shown in "Figure 3 multiple episodes of transfusion" most of them were severe anemic and hemophilic patients. 2661 units were processed to separate into various components in the blood donation center itself.

The various components supplied are out of 3225 issues 1200 whole blood units were issued to 1132 patients, 1291 packed red cells units were issued 1251 patients, 237 fresh frozen plasma units were issued 215 patients, 482 platelet rich plasma units were issued 457 patients, 15 platelet rich concentrate units were issued 15 patients.

The most common condition for transfusions was found to be anemia $(n=1625 / 3225,50.3 \%)$ as shown in "Figure 4 frequent indications for transfusion". Largest number of units were supplied to General Medicine $(n=1227 / 3225,38 \%)$ followed by pediatric ward $(n=515 / 3225,15.9 \%)$. Major consumption of blood and its components 
Citation: Singh SP, Nazreen H (2015) A Prospective Study of Blood Usage Pattern and Demand Supply Assessment in a Tertiary Care Hospital in India. J Blood Disord Transfus 6: 317. doi:10.4172/2155-9864.1000317

Page 3 of 4

were seen in government hospitals (92.2\%), of which $75 \%$ units were supplied to MGM hospital itself.

During the assessment of demand and supply in genders regarding donors and issues we found that prominent donors were males $94.7 \%$ when compared to females $5.3 \%$. When issues were assessed it was found that female population received $54.6 \%$ transfusion units than male population $45.3 \%$ units as shown in "Table 1 gender wise demand supply comparison".

The comparison of mean age of the donors and receptors are shown in the "Table 2. Donor vs. Issues Age Distribution".

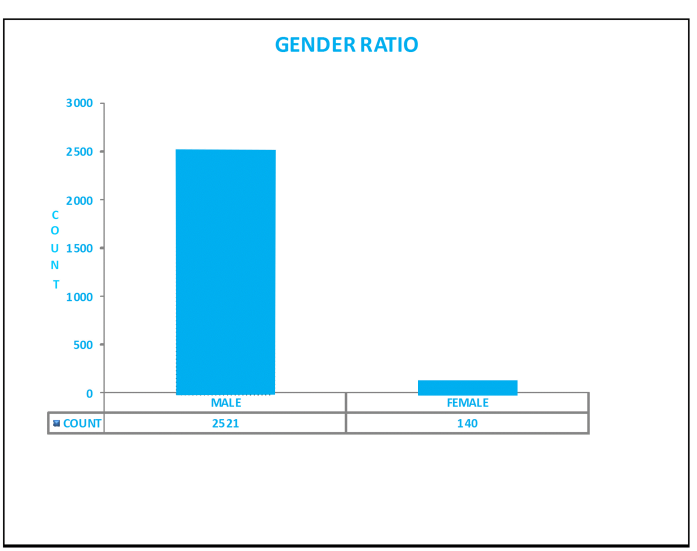

Figure 1: Gender comparison of donors.

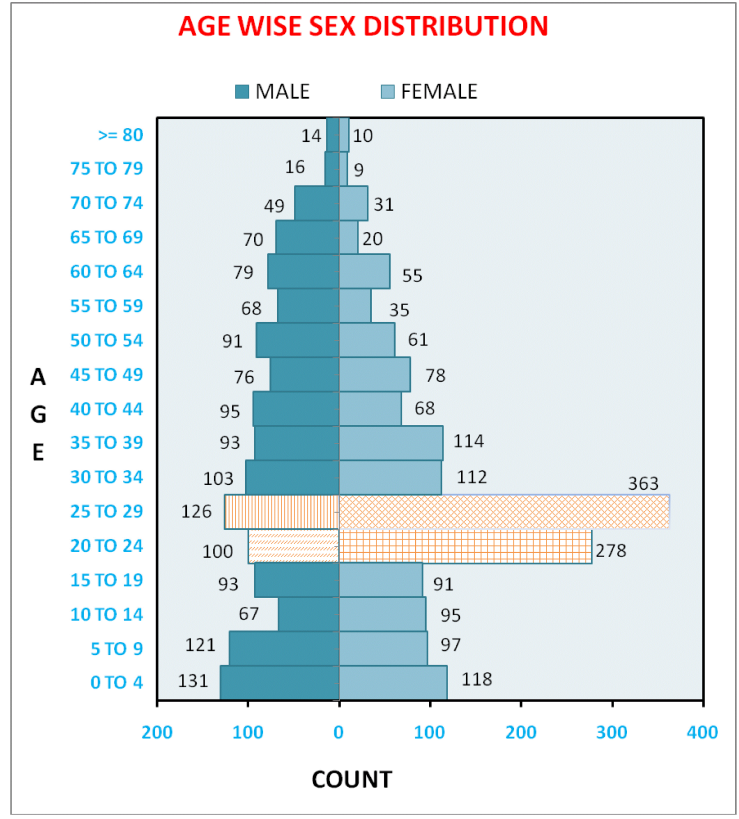

Figure 2: Age wise sex distribution of recipients.

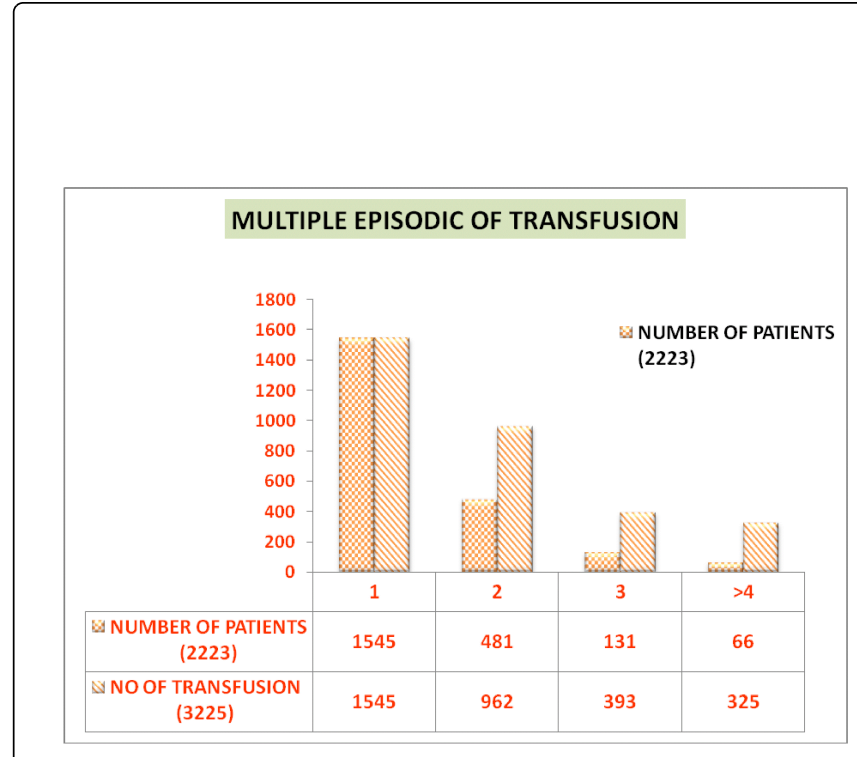

Figure 3: Multiple episodes of transfusion.

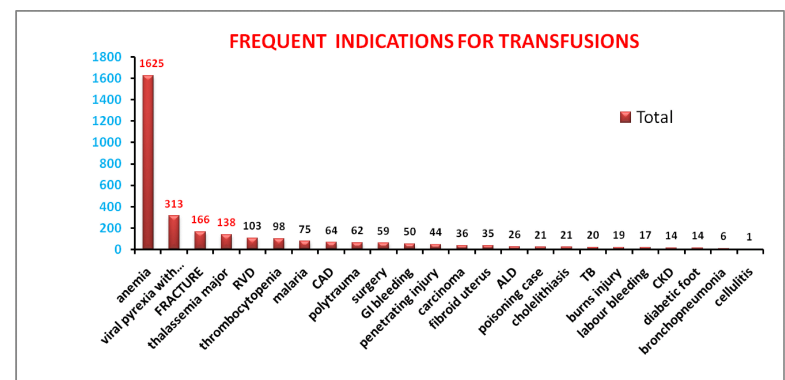

Figure 4: Frequent indications for transfusion.

\begin{tabular}{|l|l|l|}
\hline Variable & Donor (2661) & Receptors (3225) \\
\hline Male & $2521(94.7 \%)$ & $1462(45.3 \%)$ \\
\hline Female & $140(5.3 \%)$ & $1763(54.6 \%)$ \\
\hline
\end{tabular}

Table 1: Gender wise demand supply comparison.

\begin{tabular}{|l|l|l|l|}
\hline Variable & Mean Age \pm SD & Min- Max Age & Cl \\
\hline Donors & $25.61 \pm 7.429$ & $16-77$ & $25.32-25.89$ \\
\hline Reciptors & $30.68 \pm 19.17$ & Jan-88 & $30-31.36$ \\
\hline
\end{tabular}

Table 2: Donor vs. issues age distribution. 
The mean age of donors is $25.61 \pm 7.429$, and mean age of recipients is $30.68 \pm 19.7$ with is highly significant $(\mathrm{p}<0.0001)$. There was no significant difference found between the average mean of donations per day $(32.91 \pm 11.65)$ and issues $(28.92 \pm 60.19)$ at $\mathrm{p}<0.5333$.

There was a difference of 4 units when the daily donations and issues was compared. 432 (19\%) of the donations were collected in the form of replacement i.e. in situation when the blood was unavailable/ specific group/shortage of blood in blood bank, showing the inability of blood bank to supply the blood voluntarily. 45 requests were not at all supplied which makes the count 477 (14.6\% unsupplied). The blood bank was able to fulfil $85 \%$ of the requests.

The imbalance in the demand and supply could be corrected by doing the following things:

\section{Increasing the supply}

a) The study stated that only $45(2 \%)$ of the requests were unsupplied by the blood bank but, $15 \%$ of the requests were found to be unsupplied when the replacements were included clearly showing low supplies.

b) As only 5\% donations are from females, keeping their health conditions in consideration and eligibility criteria they should be motivated to make them donation.

c) Conducting more regional and territorial camps and motivational programmes such as spreading brochures about donating blood, painting competition on painted posters instead of printed posters will boost the socks.

\section{Decrease the demand}

a) As the majority of the requests were for females and most indications were anemia. Educating females about healthy diet to overcome anemia can decrease the demand to some extent.

b) Awareness and education among all treating doctors and establishment of guidelines in wards and regular audit will prove a fruitful exercise to increase the appropriate use of blood and blood components.

\section{Conclusion}

The pilot study provides information on blood component usage in our tertiary care hospital. It demonstrates the trend of utilization of blood and blood components and demand and supply assessment in relevance with quality management of transfusion practice.

Blood donations by males were prominent and the issues were high in general medicine ward were the frequent indication was anemia in females.

The study stated that only 45 (2\%) of the requests were unsupplied by the blood bank but, $15 \%$ (which is statistically not significant) of the requests were found to be unsupplied when only voluntary donors were considered excluding the replacement donations clearly showing low supplies.

Keeping every aspect in consideration unforeseen situations may arise when there will be shortage of blood. Even though periodic review of blood component usage is very important to assess the blood utilization pattern in hospital in order to ensure availability of components to needy patients. This work concludes with a note to the personnel's of blood bank that there exists a shortage of blood donors and there is a need to correct the balance for efficient succession.

\section{References}

1. Hospital Transfusion Committee Centre Hospital Macao (2005) Blood Transfusion A clinician's reference.

2. Metz J, McGrath KM, Copperchini ML, Haeusler M, Haysom HE, et al. (1995) Appropriateness of transfusions of red cells, platelets and fresh frozen plasma. An audit in a tertiary care teaching hospital. Med J Aust 162: 572-573, 576-7.

3. Luk C, Eckert KM, Barr RM, Chin-Yee IH (2002) Prospective audit of the use of fresh-frozen plasma, based on Canadian Medical Association transfusion guidelines. CMAJ 166: 1539-1540.

4. Toy PT (1996) Audit and education in transfusion medicine. Vox Sang 70: 1-5.

5. Barnette RE, Fish DJ, Eisenstaedt RS (1990) Modification of fresh-frozen plasma transfusion practices through educational intervention. Transfusion 30: 253-257.

6. Vishwanathan C, Jain R, Kamath M (1999) Blood utilization review in a tertiary care hospital. Indian J Haematol Blood Transf 17: 26-31.

7. Solomon RR, Clifford JS, Gutman SI (1988) The use of laboratory intervention to stem the flow of fresh-frozen plasma. Am J Clin Pathol 89: 518-521.

8. Brien WF, Butler RJ, Inwood MJ (1989) An audit of blood component therapy in a Canadian general teaching hospital. CMAJ 140: 812-815. 